\title{
Relationship between Emotion Regulation (Effortful Control) and Peer Attachment among Adolescents in Pakistan
}

\author{
A.H. Sami* and A. Ijaz \\ Private Practitioner, Islamabad, Pakistan \\ Email of corresponding author: ahanans99@gmail.com
}

\begin{abstract}
Current study was aimed to assess the relationship between emotion regulation (effortful control) and peer attachment among adolescents. Translated version of Early Adolescents Temperament Questionnaire - Revised originally developed by Ellis \& Rothbart (2001) and Inventory of Peer Attachment (Greenberg \& Armsden, 1987) was used to measure emotion regulation (effortful control) and peer attachment respectively. Sample consisted of 100 participants (age range $=12-16$ years) from government and private schools of Rawalpindi and Islamabad. Techniques used for sampling were purposive- convenient as adolescents willing to participate were included in the study. Psychometric properties of EATQ-R and IPA-R were analyzed. Alpha reliabilities for both scales were found to be satisfactory. Participants scored low on emotion regulation and peer attachment; therefore, negatively skewed data was generated. It was also found that emotion regulation (effortful control) and peer attachment have significant negative relationship with each other. Moreover, demographic variables were found to be associated with emotion regulation (effortful control) and peer attachment among adolescents in Pakistan.
\end{abstract}

Keywords: Emotion Regulation; Effortful Control; Peer Attachment; Activation Control; Inhibition Control; Alienation.

\section{INTRODUCTION}

The emotional behavior of humans has been a topic of great debate in history. Some researchers consider emotions as useless with no functional aspects whereas others view them as contributing to individual's adaptation to his environment (Schwarz \& Clore, 1983). The effectiveness of this adjustment depends upon quality of emotion regulation. Emotion regulation can be regarded as including both automatic as well as effortful control of emotions (Gross, 1998). This regulation of emotions is influenced by relationship with parents in childhood and peers in adolescence. Several studies confirm the existence of relationship between the two hypothetical constructs. The relationship between emotion regulation (effortful control) and peer attachment can be considered reciprocal in nature where both affect each other. A research conducted by Contreras, Kerns, Weimer, Gentzler, \& Tomich (2000) supported the idea that secure peer attachment leads to constructive coping of emotions. Likewise, emotions also serve an important role in establishing successful social relationships. Researches also reveal that adolescents with adequate emotions enjoy good quality relationships with others (Lopes, Salovey, Beers, \& Cote, 2005).

\section{DIFFERENCE BETWEEN EMOTIONS, STRESS AND MOOD}

Emotions can be distinguished from other affective processes like stress and mood. Stress and emotions can be considered alike in that both involve physiological responses to situation encountered. Where emotions refer to the responses that are either positive or negative, stress carries negative connotation and reflects unspecified response to a stimulus (Lazarus, 1993).

Mood can be distinguished from emotion on the basis of time span and the range of action tendencies it arises. Mood persists for a longer period of time as compared to emotions and contains broad range of action propensities that bias individual's cognitions (Gross, 2007).

Though different, the three affective processes are similar to some extent. These emotional states can be controlled through emotion regulation process. Successful emotion regulation permits an 
individual to adjust well in his environment. If an individual is unable to regulate emotions, his psychological health can be disrupted (Kring \& Werner, 2004).

\section{EMOTION REGULATION}

Thompson (1994) viewed regulation of emotions as analysis and modification of one's emotions and their intensity in context of the situation encountered. Emotion regulation is a natural phenomenon that permits children to manage their emotions along with altering their expressions in contrast to what they actually feel (Saarni, 1989). Effortful control develops as a part of early process of emotion regulation in children. It includes variety of actions like initiation and inhibition of actions to control emotional responses (Balter \& Tamis, 2006).

According to Rothbart and Bates (as cited in Eisenberg, 2006), effortful control involved an ability to activate a secondary response by inhibiting a dominant one. As the name implies, effort is needed to control one's abilities in effortful control. Using effortful control, individual is better able to cope with the situation by acting according to the situation and preventing the undesirable behaviors. It also involves focusing and shifting one's attention that plays an important role in regulation of emotions.

Emotion regulation in adolescents is closely related to social interactions that mainly include peers who serve as attachment figures. Adolescents acquire ability to generalize the attachment pattern learned in childhood to form strong ties with their peers with whom they can share their feelings. This peer attachment serves an important function in regulating emotions effectively when the child is distressed (Allen \& Miga, 2010).

\section{PEER ATTACHMENT}

Peer attachment or friendship encompasses a close and informal connection between two or more individuals as is suggested by many theorists. Armsden \& Greenberg (1987) considered peer attachment as an emotional tie that is experienced with significant strength. Maintaining this strong bond rests upon the level of trust and openness along with quality time spent with one's social circle. The more trustworthy an individual considers his peers to be, more is the disclosure and vice versa. Whereas, if an individual is unable to feel safe and supported by his/her peers, he might become distant and prefer being aloof. Other theorists expanded the idea by defining peer attachment as the most intimate emotional bond chosen at one's own will and characterized by reciprocated rights and freedom from selfcenteredness. Lewis (2010) defined peer attachment in terms of shared goals of two individuals. According to him, friendship is a companionship that arises when two individuals realize that they have common interests and opinions.

Attachment bonds grow out of childhood and continue to influence individual even in adolescence. They enable an individual to learn optimal ways to interact with others control his social behavior and develop age relevant skills to communicate his feelings to others (Parker \& Asher, 1987). As a result, they might be able to understand others' problems and facilitate their sense of self-worth (Hunt \& Hardt, 1965).

\section{RELATIONSHIP BETWEEN EMOTION REGULATION (EFFORTFUL CONTROL) AND PEER ATTACHMENT}

Emotion regulation has gained great significance among functionalist theorists who rely on the fact that emotion regulation is nurtured by social interactions among individuals. These social relationships provide a means to exercise strategies for regulating or controlling emotions that in turn result in strengthening of affiliation ties.

Other than parents, peers play a vital role in opting the ways to control emotions in adolescence. The level of intimacy with peers makes effective regulation of emotions possible. Sense of being understood and provision of support facilitates the management of emotions and their arousal (Thompson, 1995). This idea was concurrent to the findings proposed by Field (1995). He conducted a study that revealed that a child with satisfactory relationship with peers can cope with emotional distress with more ease than children with unresponsive peers.

Emotion regulation can also be enhanced by influencing one's attribution style by giving 
responses like "it was not your fault". Although offering such level of significant support might encourage an individual to cope effectively with his environment but drastic results can also occur. The social expectations generated towards peers might increase dependence and reduce regulation efforts leading to distress (Thompson, 1992).

\section{RATIONALE OF THE STUDY}

The domain of emotions is evolving progressively in the field of psychology. Emotions play a vital role in daily life. They might act as double- edged sword sometimes putting an individual in circumstances that he feels difficult to cope with. On the other hand, emotions might guarantee one's successful adaptation in his environment if they are being regulated adequately. Emotions can be regulated rather involuntarily or voluntarily termed effortful control considered one of the main variables in current research in relation to another variable peer attachment.

Effective emotion regulation has been linked to secure attachment with parents in childhood and later on with peers in adolescence by various researchers. Research studies conducted by Lopes and his colleagues in 2005 concluded that positive relationship exists between efficient emotional control and quality relationships with others in adolescence. Similar findings were reported by Allen \& Miga (2010). The purpose of present study was to validate the relationship between an aspect of emotion regulation known as effortful control (consisting of activation, attention and inhibition) and peer attachment among adolescents in Asian culture. The study was aimed to get knowledge of relationship between emotion regulation and social interaction with significant others that mainly included peers in adolescence.

\section{METHODOLOGY}

\subsection{Objectives}

Objectives of the present research were

1) To explore the relationship between emotional regulation (effortful control) and peer attachment.

2) To assess the relationship between demographic variables and emotion regulation.

3) To analyze association between demographic variables and peer attachment.

\subsection{Hypotheses}

Tentative assumptions considered for current study were

1) Greater the peer attachment; more will be emotional regulation.

2) There exists a correlation between demographic variables and emotion regulation.

3) Demographic variables and peer attachment are associated with each other.

\subsection{Research Design}

Cross sectional survey design was used to study emotional regulation and peer attachment among adolescents. Private and government school girls and boys were selected from Rawalpindi and Islamabad. Students were visited once for the sake of information gathering.

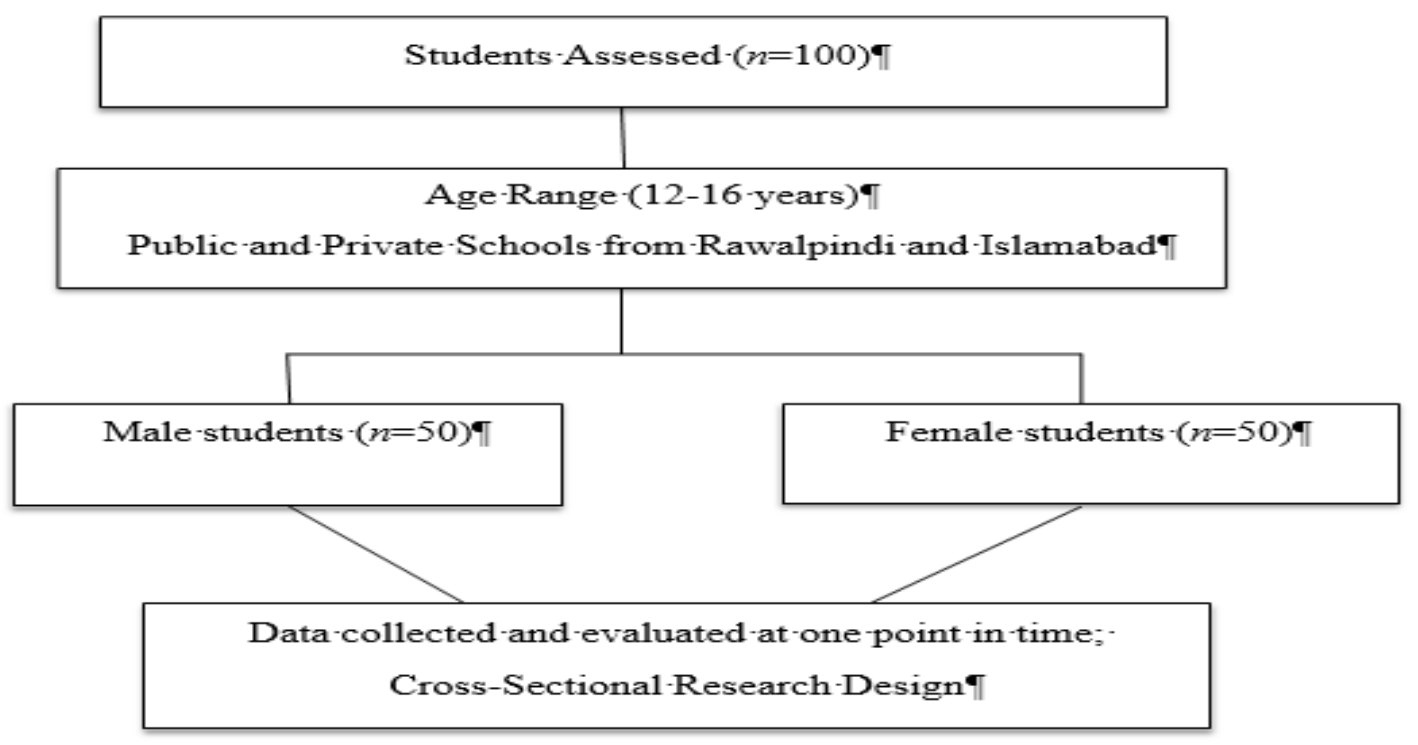




\subsection{OPERATIONAL DEFINITIONS}

Emotional Regulation: According to Ahadi \& Rothbart (1994), it is the capacity to control one's positive or negative emotional responses. Emotion regulation is generally defined in terms of effortful control.

Effortful Control: It can be described as the ability to attend to a particular stimulus along with activating a secondary response by inhibiting the central one. It also includes planning and resolution of problems (Rothbart \& Bates, 2006).

Alpha reliability for main scale was found to be within a range of .65 to .82. Higher score on effortful control indicates that individual tends to exhibit less negative emotions and behavioral problems, whereas low score indicates low social competence and pro-social behavior. Effortful control is characterized by following dimensions.

Activation: According to Rothbart \& Bates (2006), it is the tendency to accomplish an action despite strong desire to escape from it. Alpha reliability for activation control was reported as .76 for revised version.

Attention: It refers to capability of an individual to shift attention from another task and focusing it on the desirable one. Alpha reliability was stated as .67 for attention subscale (Rothbart \& Bates, 2006).

Inhibition: It means inhibiting unwanted actions and performing adequate responses. Inhibitory control was narrated to have an alpha reliability as .69 (Rothbart \& Bates, 2006).

According to Ellis \& Rothbart (2001), higher score on every subscale indicates greater intensity of attribute possessed by the individual. Individuals who score higher on effortful control are less fearful and possess lesser anger and discomfort.

Peer Attachment: According to Armsden \& Greenberg (1987), it is characterized by how an individual perceives (secure or insecure) his relationship with his intimate friends and their contribution to psychological well-being. High score on peer attachment is an indicative of secure attachment pattern whereas low score characterizes poor attachment with significant figures. Peer attachment is comprised of three subscales
Trust: Armsden \& Greenberg (1987) viewed trust as confidence adolescent has in attachment figures (peers) that they understand him and are sensitive to his psychological wants. High score on trust indicates higher reliance upon peers by individual.

Communication: It refers to the degree of openness and quality of verbal exchange with peers. Higher score on this subscale represents good communication level with peers (Armsden \& Greenberg, 1987).

Alienation: According to Armsden \& Greenberg (1987), alienation is the hostility towards or aloofness from peers. All the items belonging to alienation subscale are reverse scored; therefore, higher score on alienation subscale characterizes less detachment from peers and vice versa.

\section{INSTRUMENTS}

Early Adolescent Temperament Questionnaire - Revised: Urdu version of the Early Adolescent Temperament Questionnaire-Revised (EATQ- R) by Jabeen, Anis-ul-Haque, \& Riaz, (2013) was used to assess emotion regulation among adolescents. The scale was originally developed by Capaldi \& Rothbart (1992) and later revised by Ellis \& Rothbart (2001). Rating on temperament scale is done using 5-point Likert scale with one representing almost always untrue and five representing almost always true. Questionnaire for emotion regulation consists of total 26 items compromising of three subscales according to Ellis \& Rothbart (2001)

1) Activation Control: It consists of items 1, $2,3,4,5,6,7,8$. It measures the extent to which an individual is capable of performing an action when he is not willing to do so.

2) Attention: It includes items numbered from 9 to 15 in questionnaire. Attention subscale measures the ability to focus on a preferred task.

3) Inhibitory Control: Inhibition subscale comprises of items 16-26 of the form. Inhibitory control assesses the tendency of an adolescent to inhibit undesirable behavior.

Reverse items in the emotion regulation scale were $1,2,4,8,10,11,12,14,16,19,20,21,22$ and 23 . Alpha reliability for EATQ-R was reported as 0.74 . The scale was found to possess Convergent validity (Jabeen, Anis-ul-Haque, \& Riaz, 2013). 
Inventory of Peer Attachment - Revised (IPA-

R): In the present study, revised version of Inventory of Peer Attachment translated by Zafar (2009) was used. It was originally designed by Greenberg \& Armsden (1987) to assess the level of closeness with friends among adolescents. The IPA, based on the attachment theory of Bowlby (1969) was developed to assess the impact of strong relationship with peer adolescents ranging 12 years and older. It comprises of 25 peer items rated on five point Likert- scale assessing three vast dimensions including

1) Peer Trust: Items numbered $5,6,8,12,13,14$, $15,19,20,21$ that assess the degree of mutual trust scored directly. This dimension evaluates the confidence an individual has in his friends that they are understanding and responsive.

2) Quality of Communication: It is measured by item 1, 2, 3, 7, 16, 17, 24 and 25. It indicates the degree of openness with peers.

3) Extent of Alienation: Items numbered 4, 9, 10, 11, 18, 22 and 23 measure alienation towards peers.

Alpha reliability for peer attachment was found to be .92 (Armsden \& Greenberg, 1987). The scale has been reported to possess Convergent validity. Reverse scoring method was employed to items including 4, 5, 9, 10, 11, 18, 22 and 23 that were added to get the total values of response (Zafar, 2009).

\section{SAMPLE}

Sample consisted of hundred subjects from government and private schools of Rawalpindi and Islamabad. Sample consisted of adolescents who were willing to be a part of the study. Questionnaires were administered to subjects and their responses were analyzed to assess the relationship between peer attachment and effortful control among adolescents ranging from 12-16 years $(\mathrm{M}=14.14, \mathrm{SD}=1.34)$.

\begin{tabular}{|lll|}
\hline Variable & Categories & Frequency \\
Gender & Female & 50 \\
& Male & 50 \\
Age (years) & 11 & 3 \\
& 12 & 11 \\
& 13 & 14 \\
\hline
\end{tabular}

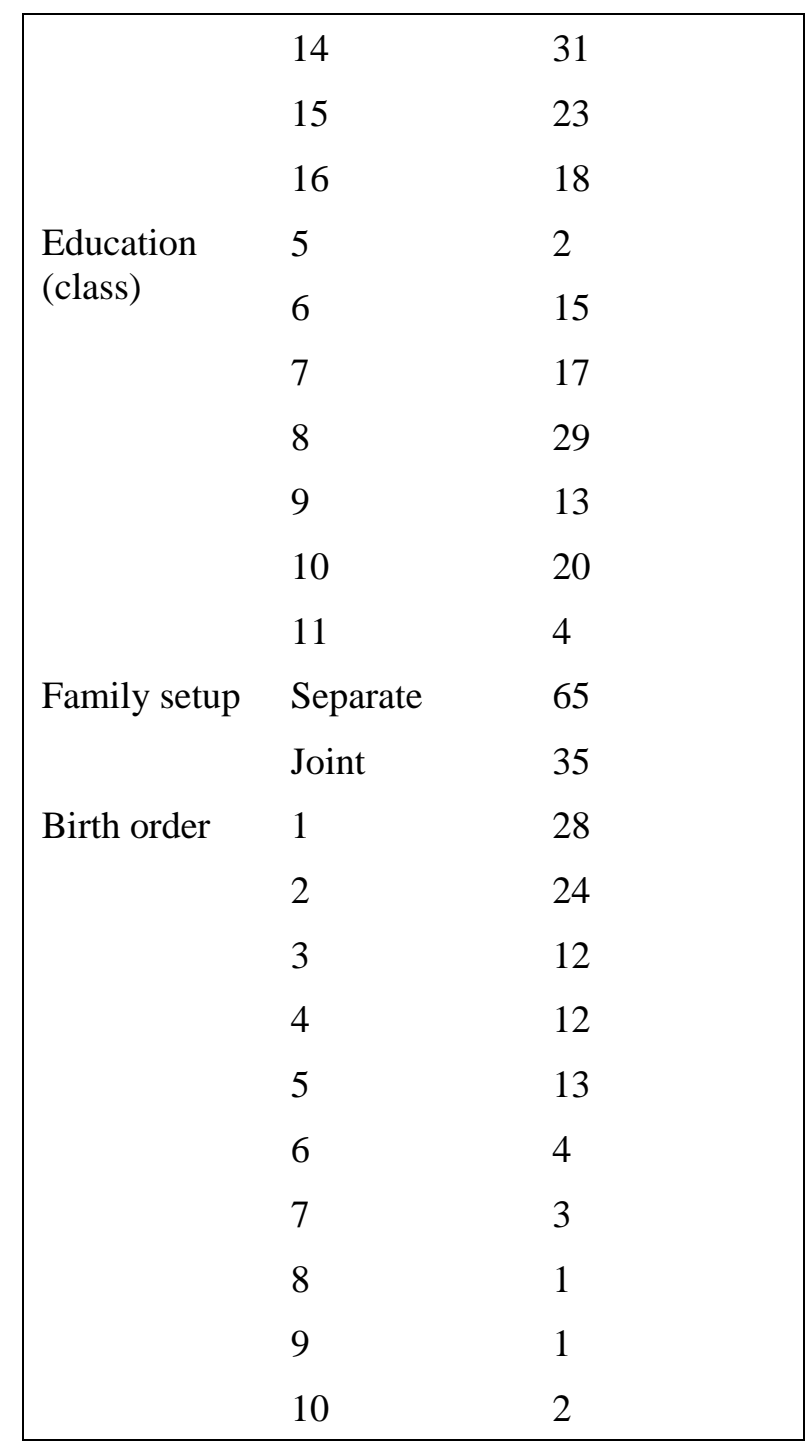

\section{PROCEDURE}

Revised versions of Emotion Regulation Questionnaire and Inventory of Peer Attachment were used to conduct study. Permission was taken from authors of questionnaires to use their scales. A sample of 100 students (age range $=12-16$ years) was surveyed. Private and government schools of Rawalpindi and Islamabad were visited to conduct the study. Permission was taken from principal and teacher of the school to collect data from students. Prior to conducting study, participants were made aware of the terms and conditions of the study and their informed consent was taken. Only those conforming to the terms and conditions and participating voluntarily were included in the study. Confidentiality of the information conveyed by the participants was ensured. All the necessary instructions regarding questionnaire completion were given to the participants. Cross- sectional survey design was used and purposive sampling 
was done to assess the possible relationship between two variables under study. Participants were presented with the questionnaires measuring emotional regulation and peer attachment.

\section{STATISTICAL ANALYSIS}

The aim of current study was to find the relationship between emotion regulation (effortful control) and peer attachment among adolescents. Moreover, association between demographic variables and study variables was explored. Data was collected from government and private schools of Rawalpindi and Islamabad for this purpose $(n=100)$. After data collection, it was analyzed using SPSS. Alpha reliabilities were calculated to assess internal consistencies for scales and subscales. Relationship among variables was evaluated using Pearson Correlation analysis for normally distributed data along study variables and values were presented in the form of tables.

Psychometric properties were calculated for the scales of present study.

\section{RESULTS}

Table 1: Psychometric Properties of Inventory of Peer Attachment- Revised and Early Adolescent Temperament Questionnaire -Revised (N=100)

\begin{tabular}{|c|c|c|c|c|c|c|c|}
\hline \multirow[t]{2}{*}{ Variable } & \multirow[t]{2}{*}{$\mathbf{N}$} & \multirow[t]{2}{*}{$\mathbf{M}$} & \multirow[t]{2}{*}{ SD } & \multirow[t]{2}{*}{$\alpha$} & \multicolumn{2}{|c|}{ Range } & \multirow[t]{2}{*}{ Skewness } \\
\hline & & & & & Potential & Actual & \\
\hline Activation & 100 & 21.24 & 4.39 & .30 & $8-40$ & $12-30$ & .08 \\
\hline Attention & 100 & 18.78 & 3.79 & .30 & $7-35$ & $9-27$ & -.22 \\
\hline Inhibition & 100 & 31.46 & 6.08 & .50 & $11-55$ & $18-45$ & -.02 \\
\hline Effortful Control & 100 & 71.48 & 9.79 & .61 & $26-130$ & $47-95$ & .05 \\
\hline Trust & 100 & 39.77 & 8.31 & .85 & $10-50$ & $10-50$ & -1.17 \\
\hline Communication & 100 & 28.95 & 6.34 & .80 & $8-40$ & $10-40$ & -.85 \\
\hline Alienation & 100 & 23.88 & 5.12 & .60 & $7-35$ & $7-33$ & -.66 \\
\hline Peer Attachment & 100 & 92.60 & 16.33 & .88 & $25-125$ & $34-121$ & -.98 \\
\hline
\end{tabular}

Note. $\mathrm{n}=$ number of cases; $\mathrm{M}=$ mean of sample; $\mathrm{SD}=$ standard deviation; $\alpha=$ alpha reliability.

Table 1 indicates psychometric properties of EATQ-R and IPA-R. Means and standard deviations of scales and subscales along with alpha reliabilities are indicated by the tables. Alpha reliabilities for all scales and subscales were found to be satisfactory. Findings suggest that data is negatively skewed for all scales and subscales except for activation and effortful control that show positive skew.

Table 2: Item-total Correlation of Activation Control of Early Adolescent Temperament Questionnaire-Revised (N=100)

\begin{tabular}{|cc|}
\hline Item no. & $\boldsymbol{r}$ \\
1 & $.31 * *$ \\
2 & $.29 * *$ \\
3 & $.21 *$ \\
4 & $.29 * *$ \\
5 & $.25 *$ \\
6 & $.37 * *$ \\
\hline
\end{tabular}

\begin{tabular}{|ll|}
\hline 7 & $.39^{* *}$ \\
8 & .16 \\
\hline *p $<.05, * * \mathrm{p}<.01$ &
\end{tabular}

Table 2 represents item-total correlation among items belonging to activation subscale. Table shows that all the items except item 8 possess significant correlations $(\mathrm{p}<.05)$.

Table 3: Item-total Correlation of Attention Subscale $(\mathrm{N}=100)$

\begin{tabular}{|ll|}
\hline Item no. & $\boldsymbol{r}$ \\
9 & $.28^{* *}$ \\
10 & $.30^{* *}$ \\
11 & .19 \\
12 & .05 \\
13 & .06 \\
14 & $.31^{* *}$ \\
15 & $.41^{* *}$ \\
\hline${ }^{*}<<.05, * * \mathrm{p}<.01$ & \\
\hline
\end{tabular}


Table 3 represents item-total correlation of attention control. Tabulated data shows that significant correlation $(\mathrm{p}<.05)$ exists between items $9,10,14$ and 15 of scale.

Table 4: Item-total Correlation of Inhibition Control $(\mathrm{N}=100)$

\begin{tabular}{|ll|}
\hline Item no. & $r$ \\
16 & .10 \\
17 & $.44 * *$ \\
18 & $.42 * *$ \\
19 & $.21 *$ \\
20 & $.26 * *$ \\
21 & .13 \\
22 & $.25 *$ \\
23 & $.39 * *$ \\
24 & $.32 * *$ \\
25 & $.44 * *$ \\
26 & $.47 * *$ \\
\hline
\end{tabular}

*p $<.05, * * \mathrm{p}<.01$

Table 4 represents item-total correlation for inhibition control. The item total correlation is significant $(\mathrm{p}<.05)$ except item 16 and 21.

Table 5: Item-total Correlation of Effortful Control of Early Adolescent Temperament Questionnaire- Revised (N=100)

\begin{tabular}{|ll|}
\hline Item no. & $r$ \\
1 & $.30^{* *}$ \\
2 & $.25 * *$ \\
3 & $.22 * *$ \\
4 & $.29 * *$ \\
5 & $.24 *$ \\
6 & $.35^{* *}$ \\
7 & $.37 * *$ \\
8 & $.18^{*}$ \\
9 & $.27 * *$ \\
10 & $.29 * *$ \\
11 & $.22 * *$ \\
12 & $.03 *$ \\
13 & $.07 *$ \\
14 & $.27 * *$ \\
\hline
\end{tabular}

Table 5 presents the item-total correlation of effortful control of Early Adolescent Temperament Questionnaire (EATQ- Revised). Results indicated that all items are significantly related to the scale $(\mathrm{p}<.05)$.

Table 6: Item-total Correlation of Communication Subscale $(\mathrm{N}=100)$

\begin{tabular}{|ll|}
\hline Item no. & $\boldsymbol{r}$ \\
1 & $.38^{* *}$ \\
2 & $.44 * *$ \\
3 & $.62 * *$ \\
7 & $.60 * *$ \\
16 & $.56 * *$ \\
17 & $.65 * *$ \\
24 & $.67 * *$ \\
25 & $.61 * *$ \\
\hline $\mathrm{p}<.05, * * \mathrm{p}<.01$ & \\
\hline
\end{tabular}

Table 6 illustrates item-total correlation for communication subscale of peer attachment. Table signifies that all the correlation for communication are significant i.e. $(\mathrm{p}<.05)$. 
Table 7: Item-total Correlation of Trust Subscale of Peer Attachment $(\mathrm{N}=100)$

\begin{tabular}{|ll|}
\hline Item no. & $r$ \\
5 & $.46^{* *}$ \\
6 & $.62 * *$ \\
8 & $.65^{* *}$ \\
12 & $.66^{* *}$ \\
13 & $.69 * *$ \\
14 & $.68^{* *}$ \\
15 & $.53 * *$ \\
19 & $.57 * *$ \\
20 & $.67 * *$ \\
21 & $.70 * *$ \\
\hline$* \mathrm{p}<.05, * * \mathrm{p}<.01$ & \\
\hline
\end{tabular}

Table 7 shows item-total correlation belonging to trust subscale of peer attachment. Correlation is significant i.e. $\mathrm{p}<.05$ among all the items.

Table 8: Item- total Correlation of Alienation Subscale $(\mathbf{N}=\mathbf{1 0 0})$

\begin{tabular}{|ll|}
\hline Item no. & $\mathbf{r}$ \\
4 & $.34 * *$ \\
9 & $.23 *$ \\
10 & $.37 * *$ \\
11 & $.43 * *$ \\
18 & $.44 * *$ \\
22 & $.33 * *$ \\
23 & $.50 * *$ \\
\hline$* \mathrm{p}<05, * * \mathrm{p}<01$ & \\
\hline
\end{tabular}

Table 8 demonstrates alienation subscale itemtotal correlation. Table indicates that significant correlation $(\mathrm{p}<.05)$ is present among items of alienation subscale.

Table 9: Item-total Correlation of Inventory of Peer Attachment- Revised (N=100)

\begin{tabular}{|ll|}
\hline Item no. & $\mathbf{r}$ \\
1 & $.38^{* *}$ \\
2 & $.46^{* *}$ \\
3 & $.62^{* *}$ \\
4 & $.30^{* *}$ \\
5 & $.46^{* *}$ \\
\hline
\end{tabular}

\begin{tabular}{|ll|}
\hline 6 & $.63 * *$ \\
7 & $.59 * *$ \\
8 & $.65 *$ \\
9 & $.23 * *$ \\
10 & $.33 * *$ \\
11 & $.41 * *$ \\
12 & $.65 * *$ \\
13 & $.70 * *$ \\
14 & $.68 * *$ \\
15 & $.54 * *$ \\
16 & $.57 * *$ \\
17 & $.64 * *$ \\
18 & $.46 * *$ \\
19 & $.58 * *$ \\
20 & $.67 * *$ \\
21 & $.67 * *$ \\
22 & $.33 * *$ \\
23 & $.52 * *$ \\
24 & $.67 * *$ \\
25 & $.60 * *$ \\
\hline $\mathrm{p}<.05, * * \mathrm{p}<.01$ & \\
\hline
\end{tabular}

Table 9 presents the item-total correlation of inventory of peer attachment (IPA). The results showed that all the items are significantly positively related to the scale $(* \mathrm{p}<.05, * * \mathrm{p}<.01)$.

Table 10: Inter-Scale Correlation of Effortful Control of Early Adolescent Temperament Questionnaire - Revised (N=100)

\begin{tabular}{lllll|}
\hline Scales & $\mathbf{1}$ & $\mathbf{2}$ & $\mathbf{3}$ & $\mathbf{4}$ \\
1 Activation & - & - & - & - \\
2 Attention & $.28^{* *}$ & - & - & - \\
3 Inhibition & $.25^{* *}$ & .04 & - & - \\
4 Effortful & $.71^{* *}$ & $.54^{* *}$ & $.75^{* *}$ & - \\
Control & & & & \\
$* *$ p $<.01$ & & & &
\end{tabular}

Table 10 shows that all the three subscales of positively related to each other and main scale. Overall, inter-scale correlation turned out to be significant $(* * \mathrm{p}<.01)$. 
Table 11: Inter-Scale Correlation of Inventory of Peer Attachment- Revised (N=100)

\begin{tabular}{|lllll|}
\hline Scales & $\mathbf{1}$ & $\mathbf{2}$ & $\mathbf{3}$ & $\mathbf{4}$ \\
1 Trust & - & - & - & - \\
2 Communication & $.82 * *$ & - & - & - \\
3 Alienation & $.35 * *$ & $.21 *$ & - & - \\
4 Peer & $.94 * *$ & $.87 * *$ & $.57 * *$ & - \\
Attachment & & & & \\
${ }^{*} \mathrm{p}<.05, * * \mathrm{p}<.01$ & & &
\end{tabular}

Table 11 indicates inter- scale correlation of peer attachment inventory. It shows that trust is positively related to communication and anger. Relationship between anger and communication is also significantly positive $(* \mathrm{p}<.05, * * \mathrm{p}<.01)$.

Table 12: Correlation Matrix between Peer Attachment and Emotion Regulation (Effortful Control) and their Subscales $(\mathrm{N}=100)$

\begin{tabular}{|lllllllll|}
\hline Variable & $\mathbf{1}$ & $\mathbf{2}$ & $\mathbf{3}$ & $\mathbf{4}$ & $\mathbf{5}$ & $\mathbf{6}$ & $\mathbf{7}$ & $\mathbf{8}$ \\
1 Trust & - & - & - & - & - & - & - & - \\
2 Communication & $.82 * *$ & - & - & - & - & - & - & - \\
3 Alienation & $.35 * *$ & $.20^{*}$ & - & - & - & - & - & - \\
4 Peer Attachment & $.94 * *$ & $.87 * *$ & $.57 * *$ & - & - & - & - & - \\
5 Activation & $-.39 * *$ & $-.29 * *$ & $-.23^{*}$ & $-.39 * *$ & - & - & - & - \\
6 Attention & $-.27 * *$ & $-.25^{*}$ & $-.23^{*}$ & $-.31 * *$ & $.26 * *$ & - & - & - \\
7 Inhibition & -.20 & -.08 & -.08 & -.16 & $.26 * *$ & .07 & - & - \\
8 Effortful & $-.40^{* *}$ & $-.28^{* *}$ & $-.24 *$ & $-.39 * *$ & $.71 * *$ & $.54 * *$ & $.77 * *$ & - \\
Control & & & & & & & & \\
\hline
\end{tabular}
*p $<.05, * * \mathrm{p}<.01$

Table 12 signifies correlation among IPA-R and EATQ-R and their subscales. Results showed that all the three subscales of inventory of peer attachment were positively related to each other.
Activation control, attention and inhibition subscales of emotion regulation scale are positively correlated to each other and effortful control. Peer attachment and effortful control were found to be negatively correlated with each other.

Table 13: Correlation of Demographic Variables with Effortful Control ( $=100)$

\begin{tabular}{|lllll|}
\hline Variable & Activation & Attention & Inhibition & $\begin{array}{l}\text { Effortful } \\
\text { Control }\end{array}$ \\
Age & $.23^{*}$ & $.11^{*}$ & $.08^{*}$ & $.20^{*}$ \\
Education & $.21^{*}$ & $.12^{*}$ & $.03^{*}$ & $.16^{*}$ \\
Father's education & $-.08^{*}$ & $-.29^{*}$ & $.01^{*}$ & $-.14^{*}$ \\
Mother's education & $.05^{*}$ & $-.28^{*}$ & $-.06^{*}$ & $-.12^{*}$ \\
Number of siblings & $.03^{*}$ & $-.00^{*}$ & $-.20^{*}$ & $-.11^{*}$ \\
Birth order & $.11^{*}$ & $-.05^{*}$ & $-.19^{*}$ & $-.08^{*}$ \\
\hline
\end{tabular}
${ }^{*} \mathrm{p}<.05,{ }^{* *} \mathrm{p}<.01$

Table 13 represents correlation of demographics with effortful control. Age and education showed positive correlation with effortful control whereas education of father and mother, number of siblings and birth order are negatively correlated. Overall, demographics have significant correlation $(\mathrm{p}<.05)$ with effortful control. 
Table 14: Correlation of Demographic Variables with Peer Attachment ( $=100)$

\begin{tabular}{|lllll|}
\hline Variable & Trust & Communication & Alienation & Peer Attachment \\
Age & $-.08^{*}$ & $-.14^{*}$ & $.02 *$ & $-.09^{*}$ \\
Education & $.00^{*}$ & $-.06^{*}$ & $.10^{*}$ & $.01^{*}$ \\
Father's education & $-.02 *$ & $-.02 * *$ & $.22 *$ & $.04 *$ \\
Mother's education & $.12^{*}$ & $.13^{*}$ & $.15^{*}$ & $.15^{*}$ \\
Number of siblings & $-.02 *$ & $.02 *$ & $.03^{*}$ & $.00^{*}$ \\
Birth order & $-.00^{*}$ & $.01 *$ & $.05^{*}$ & $.02^{*}$ \\
\hline${ }^{*}<.05, * * p<.01$ & & & &
\end{tabular}

Table 14 represents correlation of demographics with peer attachment. All other demographics except age have positive correlation with peer attachment. Table shows that all the demographics have significant correlation $(p<.05)$ with peer attachment.

\section{DISCUSSION}

Current study was aimed to find out relationship between effortful control and peer attachment among adolescents. Translated versions of Early Adolescent Temperament Questionnaire - Revised (Jabeen, Anis-ul-Haque, \& Riaz, 2013) and Inventory of Peer Attachment Revised (Zafar, 2009) were used to measure emotion regulation (effortful control) and peer attachment respectively. Dimensions of effortful control used were attention shifting, activation control and inhibitory control whereas peer attachment was assessed on three measures including trust, communication and alienation. The data was collected from 100 adolescents from public and private schools of Rawalpindi and Islamabad and after analyzing the data, results were formulated.

Psychometric properties of EATQ-R and IPA$\mathrm{R}$ were studied (see Table 1). Mean represented average scores of participants on main scales and their subscales whereas standard deviation represented clustering of data around this average. Comparison of potential and actual range indicates the discrepancy among comparison of scores expected and the real scores obtained by adolescents on both scales. Findings suggested negatively skewed data that might be due to the fact that people scored low on emotion regulation and peer attachment. Alpha reliabilities were analyzed for both scales and their relevant subscales. Reliability index for temperament scale out to be $\alpha=$.61. Research conducted by Salley et al.(2014) on effortful control in relation to social interaction of children provided evidence for EATQ-R to be reliable tool with an alpha reliability of .85 . The value of Cronbach's Alpha was found to be .88 for IPA-R. Alpha reliability for IPA-R was found to be .92 in a survey conducted by Pace, Martini, \& Zavattini (2011) on adolescents to assess perception of their relationship with peers.

Item-total correlation for Adolescent Temperament scale and subscales were analyzed (see Tables 2-5). Results showed that all items belonging to temperament scale correlated significantly $(\mathrm{p}<.05)$.

Item-total correlations were also calculated for IPA-R and its subscales (see Tables 6-9). Tables suggest that all the items are consistent with the main scale.

Inter scale correlation for effortful control was also calculated (see Table 10). Activation control, attention control and inhibition were found to be positively correlated with each other and effortful control. Relation might suggest that adolescent who is better able to focus or shift his attention and effectively perform adequate actions is more emotionally regulated than others. Moreover, adolescents who are able to perform desirable actions under stressful circumstances do not face repercussions that otherwise can be caused due to ineffective situation handling. This reduces the chances of getting distressed thus enhancing successful regulation of emotions (Rothbart \& Bates, 2006).

Inter-scale correlation indicated that all subscales of IPA-R correlated positively with the main scale respectively (see Table 11). Positive correlation might be an indication of the fact that an Individual who has strong bonding with his 
peers considers them more trustworthy. He is able to communicate with them openly and might express anger and alienation more easily towards them. Armsden and Greenberg (1987) found that trust and communication correlated negatively with the main scale whereas negative inter-scale correlation was found for alienation subscale. Reason for difference in results might be due to cultural differences (as cited in Balter \& Tamis, 2006).

It was hypothesized that there exists a positive relationship between emotion regulation (effortful control) and peer attachment (see Table 12). Findings are inconsistent with the stated assumption, therefore, hypothesis is rejected. Prior studies as conducted by Field (1995) suggested positive relationship between emotion regulation (effortful control) and peer attachment. Analysis resulted in negative correlation between the two variables. The discrepancy in results of current study might be due to difference in individual personalities, sample selected, culture and environmental factors (as cited in Balter \& Tamis, 2006). According to Thompson (1992), enhanced social expectations from intimate peers might also play role in reduced use of emotion regulating strategies. As relationship with peers gets stronger, it increases the tendency to have high expectations from close friends. When these expectations are not fulfilled, individual experiences disappointment and gets emotionally disturbed. As a result, he is unable to control his emotions.

Activation control was found to be negatively correlated with trust, communication, alienation and peer attachment in general. The relationship among the three domains and main scale was found to be significant. Activation control can be considered as an ability to perform an action when there is strong urge to avoid it. Potential reason behind this relationship might be imbedded in the fact that individuals with lesser degree of communication with peers might not have enough motivation to take inspired action and can procrastinate or the do not take any action at all to achieve their goal. Moreover, individuals with low level of trust might find it hard to rely upon their peers' and might avoid difficult task or taking any risk altogether. If an individual has open communication and considers his peers to be trustworthy, he/ she might engage in efficient actions consequently leading to better emotion regulation. Negative relationship of activation control with alienation can be attributed to the fact that an individual with absence of any kind of support from friends might experience low mood that leads to absence of motivation or lower level of energy to carry out task at hand.

Second dimension of effortful control is inhibition control that refers to capacity of an individual to suppress action perceived inappropriate by others or in general especially in the presence of strong urge to perform that action. Inhibition control came out to be negatively correlated with all three dimensions of peer attachment namely trust, communication and alienation. If individual has strong ties with his peers, he would have higher level trust and will be more open to his peers. This enhanced level of trust and communication might lead him to perform actions that sometimes might not be considered appropriate by society in general. An adolescent might be compelled to perform an unwanted action either to earn peer acceptance or to make the bond further stronger. Possible explanation for negative correlation among alienation and inhibition control might be that when an individual doesn't have a strong need to identify with his peers, he finds it easy to perform actions that he thinks might be appropriate in situational context regardless of what others would think or say.

Finally, attention control has been found to have negative association with trust, communication and alienation. Attention control means ability to focus and shift attention whenever it is desired by the individual. Results indicate that correlation is significant. Reason behind negative correlation between capacities to focus attention, trust and communication can be attributed to the fact that when person is less attached to peers, he considers them less trustworthy and does not communicate important events of his life to them. As a result, he would be less bound psychologically to focus on ideas that his peers suggest him to attend. Another explanation of this correlation in context of younger children might be that people with more intimate peers may focus more on their social circles specially peers due to which they are unable to focus on other relevant things. Their focus of attention might revolve around their peers and significant attachment figures. Attention shifting can also be affected by higher level of trust and communication. When an individual will have trust 
in his peers and communicates openly with them, he would shift his attention towards those factors considered desirable by his friends. Negative correlation between alienation and attention shifting and focusing can be reasoned as when a child would have unfriendly interaction with his/her peers, he would ignore his peers and their suggestions, thereby focusing his attention on tasks and activities that he desires. Therefore, we can say that with a higher degree of alienation/ isolation from peers, an adolescent is free to attend from a number of choices and focus on goals one considers more important.

Correlation of demographics with effortful control and peer attachment was analyzed (see Table 14). Results indicated that age and education are positively correlated with effortful control. Effortful control increases with increase in age of individual. Possible explanation for this increase might be that with increasing age, emotional intensity decreases (Barrick, Hutchinson, \& Deckers, 1989). Therefore, it might be easy for them to exercise control over weak emotions. Also, as people increase in age, they gain greater ability to control their emotions (Lawton et. al., 1992). Increase in education also increases effortful control as increase in learning might help individual to develop new strategies to cope with emotional distress. Other demographic variables including education of father and mother, number of siblings and birth order have negative correlation with capability of effortful control in adolescent. More educated parents might provide excessive instructions to their child that makes him overly dependent upon them. This heightened level of support can restrict child from developing emotion regulatory strategies and make him unable to control his emotions (Balter \& Tamis, 2006). Decrease in effortful control with increase in number of siblings and birth order can be related to level of attention provided by caregiver. With the increase in number of children, parents may become less attentive towards their elder child and find less time to spend with him/her as younger child becomes the focus of attention. This parental attribute can reduce child's tendency to adequately control his emotions (Walden \& Ogan, 1988).

Other main study variable, peer attachment was found to be negatively correlated with increasing age (see Table 15). Reason might be that as people become older, they focus more on their familial life rather than peers. Older adults want to spend more time with their children and family whereas younger people enjoy going out with their peers. It was also found that there is positive relationship between birth order and peer attachment. Young adolescent is more likely to be attached to his peers than his elder sibling as attachment with peers increases in adolescence and decreases in adult years (Gorrese \& Ruggieri, 2012). Another demographic variable, child's education might allow him to learn adequate ways of communication. This might result in foundation of stronger attachment patterns with others in his environment. Also, more educated parents serve the same purpose by making child equipped with effective ways of interacting with peers resulting in strengthening of social ties. Increase in siblings might result in caregiver becoming busy most of the time and less availability to spend quality time with the elder child. Due to this reason, attachment might be shifted from parents to peers so that adolescent can share his experiences and feelings to significant attachment figures in his life. Peers might become a source of emotional and social support and serve as major attachment figures in adolescence (Wilkinson as cited in Gorrese \& Ruggieri, 2012).

\section{CONCLUSION}

Findings of current study suggest that there exists significantly negative correlation between emotion regulation (effortful control) and peer attachment. Strong bonding with peers might result in enhanced dependence and expectations from attachment figures i.e. peer during adolescence. When these expectations are not fulfilled, one finds it unable to cope with and regulate his emotions effectively.

It was also concluded that demographic variables also play significant role in emotion regulation and peer attachment. However, they cannot be considered the sole factor bringing about a positive change or deteriorating effortful control and peer attachment among youth.

\section{LIMITATIONS AND SUGGESTIONS}

Following are some of the limitations and suggestions regarding current study 
1. Limited sample size was used in current study due to time constraint.

2. Adolescents who participated voluntarily were only made part of the study. Selecting random sample might have yielded better results.

3. Longitudinal study might prove to be more useful in analyzing patterns of emotion regulation and peer attachment during different stages of adolescence.

\section{IMPLICATIONS}

Following are the implications of present research

1. Two main variables emotion regulation and peer attachment were studied that can be helpful in field of development psychology. Development patterns of effortful control in adolescence can be analyzed.

2. Adolescents might depend excessively upon their peers and develop many expectations from them that affect them negatively. Children should be taught skills to cope with emotion arousing events and develop independence.

\section{REFERENCES}

[1] Ahadi, S. A., \& Rothbart, M. K. (1994). Temperament, development, and the Big Five. The Developing Structure of Temperament and Personality from Infancy to Adulthood, 189207.

[2] Allen, J. P., \& Miga, E. M. (2010). Attachment in adolescence: A move to the level of emotion regulation. Journal of Social and Personal Relationships, 27(2), 181-190. https://doi.org/10.1177/0265407509360898

[3] Armsden, G. C., \& Greenberg, M. T. (1987). The inventory of parent and peer attachment: Individual differences and their relationship to psychological well-being in adolescence. Journal of Youth and Adolescence, 16(5), 427454. https://doi.org/10.1007/bf02202939

[4] Balter, L., \& Tamis, C. S. (2006). Child Psychology: Handbook of Contemporary Issues.

[5] Barrick, A. L., Hutchinson, R. L., \& Deckers, L. H. (1989). Age effects on positive and negative emotions. Journal of Social Behavior \& Personality. Retreived from: http://psycnet.apa.org/psycinfo/1990- 19480-001

[6] Bowlby, J. (1969). Attachment and Loss. London: Hogarth.

[7] Capaldi, D. M., \& Rothbart, M. K. (1992). Development and validation of an early adolescent temperament measure. The Journal of Early Adolescence, 12(2), 153-173. https://doi.org/10.1177/0272431692012002002

[8] Contreras, J. M., Kerns, K. A., Weimer, B. L., Gentzler, A. L., \& Tomich, P. L. (2000). Emotion regulation as a mediator of associations between mother-child attachment and peer relationships in middle childhood. Journal of Family Psychology: JFP: Journal of Family Psychology, 14(1), 111-124. https://doi.org/10.1037/08933200.14.1.111

[9] Eisenberg, N. (2006). Relation of emotion-related regulation to children's social competence: a longitudinal study. Emotion, 6(3), 498. https://doi.org/10.1037/1528-3542.6.3.498

[10] Ellis, L. K., \& Rothbart, M. K. (2001). Revision of the early adolescent temperament questionnaire. In Poster presented at the 2001 Biennial Meeting of the Society for Research in Child Development, Minneapolis, Minnesota.

[11] Field, T. (1995). Infants of depressed mothers. Infant Behavior and Development, 18(1), 1-13. https://doi.org/10.1016/0163-6383(95)90003-9

[12] Gorrese, A., \& Ruggieri, R. (2012). Peer Attachment: A Meta-analytic Review of Gender and Age Differences and Associations with Parent Attachment. Journal of Youth and Adolescence, 41(5), 650-672. http://doi.org/10.1007/s10964-012-9759-6.

[13] Gross, J. J. (1998). The emerging field of emotion regulation: An integrative review. Review of General Psychology, 2(3), 271-299. http://doi.org/10.1037/1089-2680.2.3.271

[14] Gross, J. J., \& Thompson, R. A. (2007). Emotion Regulation: Conceptual Foundations. In Handbook of emotion regulation (pp. 3-24). New York, NY, US: Guilford Press.

[15] Hunt, D. E., \& Hardt, R. H. (1965). Developmental stage, delinquency, and differential treatment. Journal of Research in Crime and Delinquency, 2(1), 20-31. https://doi.org/10.1177/002242786500200103

[16] Jabeen, F., Anis-ul-Haque, M., \& Riaz, M. N. (2013). Parenting styles as predictors of emotion regulation among adolescents. Pakistan Journal of Psychological Research, 28(1).

[17] Kring, A. M., \& Werner, K. H. (2004). Emotion regulation and psychopathology. The Regulation of Emotion, 359-385. https://doi.org/10.4324/9781410610898-23

[18] Lawton, M.P., Kleban, M.H, Dean, J., Rajagopal, D., \& Parmelee, P.A (1992). The factorial generality of brief positive and negative affect measures. Journal of Gerontology, 47(4). https://doi.org/10.1093/geronj/47.4.p228 
[19] Lazarus, R. S. (1993). Coping theory and research: past, present, and future. Psychosomatic Medicine, 55(3), 234-247. https://doi.org/10.1097/00006842-199305000-00002

[20] Lewis, K. (2010). Beyond and below racial homophily: Erg models of a friendship network documented on facebook1. American Journal of Sociology, 116(2), 583-642. https://doi.org/10.1086/653658

[21] Lopes, P., Salovey, P., Cote, S., \& Beers, M. (2005). Emotion Regulation Abilities and the Quality of Social Interaction. Emotion, 5(1), 113-118. https://doi.org/10.1037/1528-3542.5.1.113

[22] Pace, C. S., San Martini, P., \& Zavattini, G. C. (2011). The factor structure of the Inventory of Parent and Peer Attachment (IPPA): A survey of Italian adolescents. Personality and Individual Differences, 51(2), 83- 88. https://doi.org/10.1016/j.paid.2011.03.006

[23] Parker, J. G., \& Asher, S. R. (1987). Peer relations and later personal adjustment: Are low-accepted children at risk? Psychological Bulletin, 102(3), 357. https://doi.org/10.1037/0033-2909.102.3.357

[24] Rothbart, M. K. \& Bates, A. (2006). Temperament. Developmental Neuroscience, 2, 465.

[25] Saarni, C. (1989). Children's understanding of emotion. Cambridge University Press.

[26] Salley, C. G., Hewitt, L. L., Patenaude, A. F., Vasey, M. W., Yeates, K. O., Gerhardt, C. A., \& Vannatta, K. (2014). Temperament and Social Behavior in Pediatric Brain Tumor Survivors and Comparison Peers. Journal of Pediatric Psychology, 40(3), 297-308. https://doi.org/10.1093/jpepsy/jsu083

[27] Schwarz, N., \& Clore, G. L. (1983). Mood, misattribution, and judgments of well-being: informative and directive functions of affective states. Journal of Personality and Social Psychology, 45(3), 513. https://doi.org/10.1037/0022-3514.45.3.513

[28] Thompson, C. L.(1992). Counseling children . Thomson Brooks/Cole Publishing Co.

[29] Thompson, L. A. (1995). A twin study of competence and problem behavior in childhood and early adolescence. Journal of Child Psychology and Psychiatry, 36(5), 775-785. https://doi.org/10.1111/j.14697610.1995.tb01328.x

[30] Thompson, R. A. (1994). Emotion regulation: A theme in search of definition. Monographs of the Society for Research in Child Development, 59(2- 3), 25-52. https://doi.org/10.1111/j.1540-5834.1994.tb01276.x

[31] Walden, T. A., \& Ogan, T. A. (1988). The development of social referencing. Child Development, 59(4), 12301240. https://doi.org/10.2307/1130486

[32] Zafar, H. (2009). Emotional autonomy, self-efficacy and attachment among adolescents (M. Phil thesis). National Institute of Psychology, Quaid-i- Azam University, Islamabad, Pakistan.

Received on 09-06-2021

Accepted on 19-06-2021

Published on 28-06-2021

(C) 2021 A.H. Sami and A. Ijaz; Licensee ATSK Publishers.

This is an open access article licensed under the terms of the Creative Commons Attribution Non-Commercial License (http://creativecommons.org/licenses/by-nc/3.0/) which permits unrestricted, noncommercial use, distribution and reproduction in any medium, provided the work is properly cited. 